\title{
SERUM CYTOKERATIN 18 AND CYTOKINE ELEVATIONS SUGGEST A HIGH PREVALENCE OF OCCUPATIONAL LIVER DISEASE IN HIGHLY EXPOSED ELASTOMER/POLYMER WORKERS
}

\author{
Matt Cave, MD $1,2,3$, Keith Cameron Falkner, PhD ${ }^{1}$, Latasha Henry, BS $^{1}$, Brittany Costello, \\ BS $^{1}$, Bonnie Gregory, BS ${ }^{1}$, and Craig J. McClain, MD ${ }^{1,2,3}$ \\ ${ }^{1}$ Department of Medicine Division of Gastroenterology, Hepatology, and Nutrition, University of \\ Louisville, Louisville KY \\ ${ }^{2}$ Department of Pharmacology and Toxicology, University of Louisville, Louisville KY \\ ${ }^{3}$ The Robley Rex Veterans Affairs Medical Center
}

\begin{abstract}
Objective-Cytokeratin 18 (CK18) is a novel serologic biomarker for occupational liver disease. The purpose of this study is to determine the prevalence of CK18 elevation in elastomer/polymer workers exposed to acrylonitrile, 1,3 butadiene, and styrene.
\end{abstract}

\begin{abstract}
Methods- 82 chemical workers were evaluated. CK18 was determined by ELISA and proinflammatory cytokines were measured by multi-analyte chemiluminescent detection.
\end{abstract}

\begin{abstract}
Results-39\% (32 of 82) had elevated CK18 levels which were not explained by alcohol or obesity, except in potentially 4 cases. The pattern of CK18 elevation was consistent with toxicantassociated steatohepatitis (TASH) in the majority of cases (78\%). TNF $\alpha$, IL-6, IL-8, MCP-1, and PAI-1 were increased in these workers compared to those with normal CK18 levels.
\end{abstract}

Conclusions-These results suggest a high prevalence of occupational liver disease and TASH in elastomer/polymer workers with elevated pro-inflammatory cytokines.

\section{Keywords}

1,3 butadiene; acrylonitrile; chemical workers; cytokeratin 18; elastomer workers; occupational liver disease; polymer workers; TASH; toxicant-associated steatohepatitis; styrene

\section{Introduction}

Occupational exposures to industrial chemicals may result in chronic occupational liver disease, a potentially serious health problem. While initially asymptomatic, chronic occupational liver disease may progress to cirrhosis, liver cancer, and death (1-5). Some industrial chemicals have consistently been associated with occupational liver disease, such as vinyl chloride and its association with hepatic hemangiosarcoma $(4,6,7)$. In fact, for some chemicals, the association with occupational liver disease is so strong, that exposure limits and medical surveillance programs are mandated by the Occupational Safety and

Corresponding Author and Contact Information: Matt Cave, MD, University of Louisville Department of Medicine, Division of Gastroenterology, Hepatology, and Nutrition, 505 South Hancock Street, Louisville, KY 40202, Phone (502) 852-6189, Fax (502) 852-8927, matt.cave@louisville.edu. 
Health Administration (OSHA). For example OSHA's Vinyl Chloride Standard (29 CFR 1910.1017), mandates semi-annual measurements of liver chemistries (bilirubin, alkaline phosphatase, aspartate aminotransferase or AST, alanine aminotransferase or ALT, and gamma-glutamyl transferase) in vinyl chloride or polyvinyl chloride production workers exposed for over 10 years. Unfortunately, these liver tests are frequently normal, even in advanced forms of chronic occupational liver disease $(1,8)$. Therefore, occupational hepatotoxicity is likely to be under-recognized, even in workers enrolled in medical surveillance programs specifically targeting liver disease.

Toxicant-associated steatohepatitis (TASH) is a recently named form of occupational liver disease (1). Pathologically, TASH is characterized by hepatic steatosis, inflammation, and fibrosis. Although TASH histologically resembles alcoholic steatohepatitis (ASH) and nonalcoholic steatohepatitis (NASH), it occurs in non-drinking, non-obese, subjects with occupational exposures to some industrial chemicals $(1,9,10)$. However, like ASH and NASH, TASH may be associated with elevated serum pro-inflammatory cytokines $(1,11)$. However, unlike ASH and NASH, TASH is frequently characterized by normal liver enzymes making its detection problematic $(1,8)$.

Cytokeratin 18 (CK18) is a cytoskeletal protein found in hepatocytes and other epithelial cells. Dying cells release CK18 into the extracellular compartment where they can be measured in serum. Both the whole CK18 protein (CK18 M65) and the caspase 3-cleaved fragment (CK18 M30) may be measured. While CK18 M65 measures total cell death, CK18 M30 specifically measures caspase-3 dependent (apoptotic) cell death. While NASH and ASH are characterized by hepatocellular apoptosis, non-apoptotic death (presumably oncotic necrosis) occurs in many forms of chemical hepatotoxicity $(1,12,13)$. Indeed, elevated CK18 M30 is a clinically useful biomarker for NASH, while CK18 M65 is an emerging biomarker for TASH (particularly when it occurs in the setting of normal ALT, AST, and CK18 M30) $(1,14)$.

Elastomer/polymer workers are exposed to a multitude of potentially toxic chemicals including acrylonitrile, 1,3 butadiene, and styrene (ABS). While acrylonitrile is metabolized into cyanide, a potent inhibitor of cytochrome c oxidase; 1,3 butadiene and styrene are metabolized into reactive intermediates including crotonaldehyde and styrene 7,8-oxide (1517). Regardless of its etiology, steatohepatits is invariably associated with mitochondrial dysfunction, oxidative stress and elevated pro-inflammatory cytokines $(1,11,18,19)$. On the basis of these observations, we hypothesize that ABS-exposed elastomer/polymer workers may be at risk for TASH owing to the toxicity of the metabolites of the parent compounds. The purpose of this study is to i) determine the prevalence and pattern of serum CK18 abnormalities in ABS-exposed elastomer/polymer workers, and ii) determine if workers with abnormal CK18 levels also have elevated levels of pro-inflammatory cytokines previously implicated in occupational liver disease (1).

\section{Materials and Methods}

\section{Subjects}

Clinical data and biological specimens (serum archived at $-80^{\circ} \mathrm{C}$ ) were obtained through a bio-repository which was instituted as described previously in response to a cluster of hepatic hemangiosarcomas occurring at a chemical manufacturing complex $(4,20)$. For the purposes of this study, 82 male ABS-exposed chemical workers were selected from 2 facilities. The analyzed serum samples were collected between the mid-1970's and late 1990's. All research subjects gave informed consent and institutional IRB approval was obtained prior to the initiation of this project in accordance with the 1975 Declaration of Helsinki. 


\section{Chemical Exposure Indices}

Chemical exposures were characterized based on employment records. Although workers were exposed to multiple industrial chemicals, exposures were higher for acrylonitrile, 1,3 butadiene and styrene. An index of cumulative exposure, the cumulative exposure rank month (CERM), was determined for each employee for each of these chemicals as described previously (21). Briefly, all jobs in the plant were assigned a rank from 0-6 based on level of exposure. Workers who were absent from the plant for a month were assigned a score of zero for that month, while workers with direct skin contact or high inhalational exposures were assigned a score of six. Ranks were summed yearly (maximum yearly score 72), and the CERMS were calculated through the date of specimen collection.

\section{Serum Analysis}

Routine serum liver enzymes, glucose, and lipids had previously been measured by an automated clinical chemistry analyzer and these data were obtained from the occupational toxicology database for analysis. Serum cytokeratin 18 whole protein $\left(\mathrm{M} 65^{\circledR}\right)$ and caspasecleaved fragments (M30 Apoptosense ${ }^{\circledR}$ ) were measured by ELISA (diaPharma, Columbus, $\mathrm{OH}$ ) as previously described (1). Abnormal CK18 was defined as either an M65 $\geq 300 \mathrm{U} / \mathrm{L}$ or an $\mathrm{M} 30 \geq 200 \mathrm{U} / \mathrm{L}$ based on prior studies $(1,14,22)$. The prevalence of CK18 elevation in this cohort was determined based on these parameters. The CK18 M30:M65 ratio was determined by dividing serum CK18 M30 by M65. Serum cytokines were determined by multi-analyte chemiluminescent detection using Milliplex kits (Millipore, Billerica, MA) on the Luminex ${ }^{\circledR}$ (Austin, TX) platform as previously described $(1,18)$. Specifically, interleukin-6 (IL-6), interleukin-8 (IL-8), monocyte chemotactic protein-1 (MCP-1), plasminogen activator inhibitor-1 (PAI-1), and tumor necrosis factor $\alpha(\mathrm{TNF} \alpha)$ were measured. Results are reported as mean \pm standard deviation.

\section{Statistical Analysis}

Subjects were stratified into three subgroups based on CK18 levels: normal CK18 M30 and M65 (healthy workers without liver injury, group 1), elevated CK18 M65 with normal CK18 M30 (suspected TASH, group 2), and elevated CK18 M30 also with elevated CK18 M65 (other suspected liver disease, group 3). Demographic, chemical exposure, and laboratory variables were then compared between these three subgroups. Intergroup comparisons were performed by one-way ANOVA with Tukey's post-test using GraphPad Prism version 5.00 for Windows (San Diego, California). In some cases of non-parametric data, the KruskalWallis test with Dunn's post-test was utilized to determine statistical significance. Likewise, linear regression analysis was performed between serum CK18 M65 and serum aminotransferases and pro-inflammatory cytokines with all subjects grouped together also using GraphPad Prism version 5.00. A p value less than 0.05 was considered statistically significant.

\section{Results}

\section{Demographic and Cumulative Exposure Data}

Demographic and exposure data for the entire cohort of 82 subjects are given in Table 1. All workers were males. The mean age ( \pm s.d.) was $47.43 \pm 7.46$ years old. The mean BMI was $25.08 \pm 3.31 \mathrm{~kg} / \mathrm{m}^{2}$. Only two workers were obese (BMI 31 and 33). The mean alcohol consumption was $2 \pm 5.34$ drinks per week. 27 of the 82 workers reported drinking ethanol. Of these, only 3 workers consumed, on average, greater than 2 alcohol containing beverages per day. These 3 workers each reported drinking 24 such beverages weekly. Concerning the workers' chemical exposure history, the mean duration of employment was $21.57 \pm 9.17$ 
years. The mean cumulative exposures (CERMs) for acrylonitrile, butadiene, and styrene were $1123.58 \pm 425.26,1055.39 \pm 449.26$, and $944.00 \pm 352.68$ respectively.

\section{Liver Tests}

$39 \%$ (32 of 82) of workers had abnormally high serum CK18 levels. Workers were stratified into groups 1-3 based on CK18 levels (Table 2). The mean serum CK18 M65 and M30 levels for group 1 (normal CK18 M65 and M30, healthy chemical workers), group 2 (elevated M65 with normal M30, suspected TASH), and group 3 (elevated CK M65 and M30, other suspected liver disease) were respectively $107.57 \pm 63.36$ and $32.80 \pm 38.63 \mathrm{U} / \mathrm{L}$; $444.43 \pm 87.98$ and $103.19 \pm 38.51 \mathrm{U} / \mathrm{L}$; and $541.88 \pm 175.32$ and $317.3 \pm 93.31 \mathrm{U} / \mathrm{L}$. The mean CK18 M65 levels were significantly higher for both groups 2 and 3 vs. group $1(\mathrm{p}<0.001)$; and for group $3 v s$. group 2 ( $<<0.05$ ). The mean CK18 M30 levels were significantly higher for both groups 2 and $3 v s$. group 1; and for group $3 v s$. group $2(\mathrm{p}<0.001)$. The CK18 M30:M65 ratio was significantly lower in group $1(33.43 \pm 37.34 \%, \mathrm{p}<0.01)$ and group 2 $(23.06 \pm 7.64 \%, \mathrm{p}<0.05) v s$. group $3(61.90 \pm 21.82 \%)$, but not $v s$. each other.

Mean routine liver chemistries (AST, ALT, total bilirubin, albumin, and alkaline phosphatase) were in the normal range for all groups (Table 2). In fact, only 3 of 82 total subjects ( 1 subject from each group) had any lab abnormality on routine liver tests. One subject from group 1 had mildly elevated ALT (94 U/L, reference range 0-55) and AST (53 $\mathrm{U} / \mathrm{L}$, reference range $0-50$ ). A single subject from group 2 and a mild alkaline phosphatase elevation to $157 \mathrm{U} / \mathrm{L}$ (reference range 25-140); while one subject from group $3 \mathrm{had}$ an isolated ALT elevation to $64 \mathrm{U} / \mathrm{L}$. Although mean ALT activity was significantly higher in group $2(23.67 \pm 11.98 \mathrm{U} / \mathrm{L})$ compared to group $1(14.82 \pm 14.1 \mathrm{U} / \mathrm{L})(\mathrm{p}<0.05)$, all workers in group 2 had ALT levels within the normal reference range. 30\% of workers ( 25 of $82-$ group 2) had a serum biochemical signature consistent with TASH (elevated CK18 M65 with normal CK18 M30, AST, and ALT). Using pooled data from all subjects, linear regression analysis found a significant positive correlation between CK18 M65 and ALT $\left(\mathrm{r}^{2}=0.1732, \mathrm{p}=0.0001\right)$ but not AST (Table 3$)$.

Concerning the 3 workers who drank greater than 2 alcoholic beverages daily, 2 of these were in group 2, while the other was in group 1. AST and ALT activities were normal in all three cases with ALT ranging from 10-12 U/L and AST ranging from 13-17 U/L.

Concerning the two workers who were obese, one worker was in group 1 while the other was in group 3. Both of these workers had normal liver enzymes with ALT activities ranging from 21-29 U/L and AST activities ranging from 20-24 U/L.

Demographic and exposure data were then determined for groups 1-3. There were no significant differences for either age, BMI, or duration of employment between groups (Table 1). Unexpectedly, acrylonitrile cumulative exposures (CERM) were significantly higher in group $1(1316.11 \pm 252.46)$ than in either group $2(805.86 \pm 476.58)(\mathrm{p}<0.001)$ or 3 $(591.96 \pm 282.28)(\mathrm{p}<0.001)$. Cumulative butadiene exposures were also significantly higher in group $1(1240.69 \pm 327.97)$ than in either group $2(740.19 \pm 473.25)(\mathrm{p}<0.001)$ or 3 $(597.98 \pm 284.53)(\mathrm{p}<0.01)$. Likewise, cumulative styrene exposures were also significantly higher in group $1(1097.73 \pm 214.42)$ than in either group $2(681.20 \pm 406.18)(\mathrm{p}<0.001)$ or 3 (571.98 \pm 252.68$)(\mathrm{p}<0.01)$. Cumulative acrylonitrile, butadiene, or styrene exposures were not significantly different between groups 2 and 3 . Thus the incidence of suspected TASH or other liver disease did not appear to increase with ABS exposures.

\section{Blood Glucose and Lipids}

Overall, 20\% of subjects had impaired fasting glucose as defined by the World Health Organization as fasting glucose values between 110 and $126 \mathrm{mg} / \mathrm{dL}$, and one had diabetes. 
In group 1, 26\% (13/50) subjects had elevated fasting blood glucose, but only one had a blood sugar in the diabetic range ( $>126 \mathrm{mg} / \mathrm{dL})$. The remaining 12 subjects had impaired fasting glucose. $12 \%(3 / 25)$ of subjects in group 2 and 14\% (1/7) subjects in group 3 had impaired fasting glucose and none had diabetes. The mean glucose values were $108.70 \pm 33.04,99.28 \pm 10.33,101.20 \pm 6.76 \mathrm{mg} / \mathrm{dL}$ for groups $1-3$ respectively and were not different between groups (Table 2).

Overall, 20\% (16/82) of subjects had hypertriglyceridemia defined by the American Heart Association as values $>199 \mathrm{mg} / \mathrm{dL} .18 \%(9 / 50), 20 \%(5 / 25)$, and $28 \%(2 / 7)$ of subjects in groups $1-3$ respectively had hypertriglyceridemia. The mean triglycerides were $167.73 \pm 153.99,163.29 \pm 67.25,167.17 \pm 130.36 \mathrm{mg} / \mathrm{dL}$ for groups $1-3$ respectively and were not different between groups (Table 2).

\section{Pro-inflammatory Cytokines}

Mean pro-inflammatory cytokines were higher in workers with suspected liver disease than those with normal CK18 (Table 4). Mean TNF $\alpha$ was higher in both groups $2(9.76 \pm 5.02 \mathrm{pg} /$ $\mathrm{ml}, \mathrm{p}<0.001)$ and $3(5.72 \pm 4.78 \mathrm{pg} / \mathrm{ml}, \mathrm{p}<0.05) v s$. group $1(0.73 \pm 2.35 \mathrm{pg} / \mathrm{ml})$. Group 2 had a higher mean IL-6 $(7.45 \pm 4.92 \mathrm{pg} / \mathrm{ml})$ than both group $1(1.62 \pm 2.85 \mathrm{pg} / \mathrm{ml}, \mathrm{p}<0.001)$ and group $3(4.98 \pm 4.01 \mathrm{pg} / \mathrm{ml}, \mathrm{p}<0.05)$. IL-8 was higher in group $2(5.67 \pm 5.78 \mathrm{pg} / \mathrm{ml})$ than in group $1(1.79 \pm 2.92 \mathrm{pg} / \mathrm{ml}, \mathrm{p}<0.01)$. However, IL-8 was no different in group $3(3.01 \pm 2.64$ $\mathrm{pg} / \mathrm{ml}$ ) than in either groups 1 or 2 . Likewise, serum MCP-1 was higher in group 2 $(283.14 \pm 122.63 \mathrm{pg} / \mathrm{ml})$ than in group $1(179.48 \pm 151.21 \mathrm{pg} / \mathrm{ml}, \mathrm{p}<0.05)$; but it was no different for group $3(243.76 \pm 101.71 \mathrm{pg} / \mathrm{ml}) v s$. either groups 1 or 2 . Similarly, mean PAI-1 was higher in group $2(42.57 \pm 50.94 \mathrm{ng} / \mathrm{ml})$ than in group $1(15.40 \pm 15.65 \mathrm{ng} / \mathrm{ml}, \mathrm{p}<0.05)$. PAI-1 was not different in group $3(17.09 \pm 7.11 \mathrm{ng} / \mathrm{ml}) v s$. either groups 1 or 2 . Using pooled data from all subjects, linear regression analyses found positive correlations between CK18 M65 and TNF $\alpha\left(\mathrm{r}^{2}=0.5596, \mathrm{p}<0.0001\right)$; IL-6 $\left(\mathrm{r}^{2}=0.4219, \mathrm{p}<0.0001\right)$; IL-8 $\left(\mathrm{r}^{2}=0.1307\right.$, $\mathrm{p}=0.0009) ; \mathrm{MCP}-1\left(\mathrm{r}^{2}=0.1625, \mathrm{p}=0.0002\right) ;$ but not PAI-1 (Table 3$)$.

\section{Discussion}

The main finding in this study is the unexpectedly high prevalence of CK18 elevation (39\%) in this cohort of ABS-exposed chemical workers with normal liver enzymes. The observed CK18 elevations were not explained by obesity or ethanol, except possibly in 4 cases. However, in each of these cases, AST and ALT activities where well within the normal range, arguing against NASH which is typically associated with ALT elevation and ASH which is typically associated with AST elevation. This suggests that effected workers had occupational liver disease. In the majority of cases ( 25 of 32 or $78 \%$ ), the pattern of liver test abnormalities (increased CK18 M65, normal M30, normal AST/ALT) was consistent with toxicant-associated steatohepatitis. Indeed, we recently reported on a cohort of highlyexposed vinyl chloride workers with biopsy-proven steatohepatitis featuring this same serologic pattern of liver test abnormalities (1). The ABS workers with suspected TASH (group 2) also had elevated pro-inflammatory cytokines including TNF $\alpha$, IL-6, IL-8, MCP-1, and PAI-1. Importantly pro-inflammatory cytokine elevation was previously reported in TASH and may be an important disease mechanism (1). We believe that these findings support our hypothesis that subjects in group 2 have TASH attributable to ABS exposures. While we believe that subjects in group 3 also have liver disease, we have not previously encountered this pattern of liver test abnormalities (increased CK18 M30 with normal AST/ALT) before in chemical workers. Therefore, we cannot make any supposition regarding the histopathologic lesion in these workers. However, we believe that these workers are truly different from those in group 2 because there were also differences in cytokine levels between these two groups. The positive correlation between CK18 M65 and ALT supports the hypothesis that the CK18 elevations observed in these chemical workers 
were in fact due to liver injury. The lack of correlation between CK18 M65 and AST in this cohort was not surprising because these subjects did not drink significant amounts of alcohol. Furthermore, the pattern of serum transaminases (ALT>AST) observed in this study was similar to what we previously noted in a different cohort of chemical wokers (1).

Importantly, the $30 \%$ prevalence of suspected TASH in elastomer/polymer workers is consistent with that noted for other etiologies of steatohepatitis. Only 20-35\% of alcoholics develop alcoholic steatohepatitis while only $25-55 \%$ of obese subjects develop nonalcoholic steatohepatitis $(19,23)$. Therefore, it is hardly surprising that not all exposed chemical workers developed suspected TASH in the present study. This moderate prevalence (30\%) of suspected TASH in ABS workers is in contrast to the extremely high prevalence (80\%) of biopsy-proven TASH in our previous study of highly-exposed vinyl chloride workers. These findings are not unexpected because acrylonitrile, 1,3 butadiene, and styrene are certainly recognized to have less hepatotoxic potential than vinyl chloride. Although there is little experimental data to support the hepatotoxicity of 1,3 butadiene, the hepatotoxic potential of styrene (centrilobular hepatic necrosis) and, to a lesser degree, acrylonitrile have been documented (24-26). To our knowledge, experimental studies on ABS mixtures have not been performed.

Although not specifically addressed in this study, we believe that the CK18 M30:M65 ratio, may be able to differentiate chemical liver injury (TASH) from obesity-related liver injury (NASH), as TASH seems to be characterized by a lower ratio reflective of caspase-3 independent (presumably necrotic) cell death. In this study, the CK18 M30:M65 ratio in ABS workers suspected of having TASH was $33 \%$. This relatively low ratio was consistent with that observed in our cohort of biopsy-proven vinyl chloride-related TASH (26\%), and is much lower than the ratios historically reported in adult (55\%) and pediatric (59\%) obesity-related NASH studies $(1,22,27)$, as well as alcoholic hepatitis (28). Interestingly, although the absolute levels of both CK18 M30 and M65 were normal in group 1, the CK18 M30:M65 ratio was lower than healthy controls from our previous study who did not work in the chemical industry and thus did not have high-level industrial chemical exposures (33\% vs. 76\%) (1). These findings suggest that chemical exposures could affect the mode of hepatocyte death even when the level of hepatocyte death is in the normal range. Although much work needs to be done, we believe that CK18 ratios could potentially differentiate TASH from NASH, and this may be reflective of differences in cell death mechanisms in these pathologically similar forms of steatohepatitis. The precise cellular mechanisms behind these observed differences are, as yet, unknown.

Interestingly, subjects with suspected TASH in this study had significantly lower cumulative ABS exposure than subjects with normal CK18 levels. This suggests that TASH may not necessarily be a dose-dependent exposure phenomenon. We hypothesize that susceptibility factors which were not evaluated in this study could be critically important in TASH.

Specifically, genetic and nutritional susceptibility factors could be relevant for TASH just as they are in ASH and NASH $(11,19)$. Genetic polymorphisms in enzymes implicated in the metabolism of industrial chemicals (cytochrome P450 2E1, or Cyp2E1, and glutathione Stransferases, or GST) influenced chemical toxicity in previous studies $(29,30)$. Importantly, the $30 \%$ prevalence of suspected TASH in our study is similar to the previously reported prevalence of GST polymorphisms in white populations (20-45\%) (31). We hypothesize that Cyp2E1 and GST genotype may have influenced the development of suspected TASH in our cohort, and future studies should examine this possibility. Limited data suggest that diets high in antioxidants are protective against NASH, and could likewise be protective against TASH, although this has not been studied $(32,33)$. However, fatty meals have been shown to increase absorption of inhaled 1,3 butadiene by changing the partition coefficient (solubility) of this lipid-soluble chemical in blood (34). Therefore, differences in diet could 
alter systemic exposure to at least some of the hepatotoxicants in this study. Therefore, we believe that genetic and nutritional susceptibility factors may have influenced the development of suspected TASH in this cohort which did not appear to be entirely explained by cumulative exposure.

Workers with suspected TASH had higher mean levels of multiple pro-inflammatory cytokines including IL-6, IL-8, MCP-1, PAI-1, and TNF $\alpha$, than workers with normal CK18 levels. We have previously reported abnormally high IL-6, IL-8, and TNFa levels in chemical workers with TASH (1). Although PAI-1 and MCP-1 elevations have not to our knowledge been reported in chemical workers with TASH, they certainly have been implicated in other etiologies of steatohepatitis $(35,36)$. The cytokine elevations observed in this study provide further evidence that TASH is a pro-inflammatory lesion. Furthermore, we believe that these pro-inflammatory cytokines may play a role in the genesis and perhaps progression of TASH. The observed positive correlations between serum levels of CK18 M65 and TNF $\alpha$, IL-6, IL-8, and MCP-1 support this hypothesis.

A major limitation of our study is that neither imaging nor liver biopsies were performed. However, the finding of CK18 elevation supports future ultrasound and/or liver biopsy studies for the confirmation of liver disease in ABS-exposed elastomer/polymer workers. CK18 is expressed in all cells of epithelial origin, and it is highly expressed in hepatocytes $(37,38)$. Thus serum CK-18 may be increased by a wide variety of diseases affecting epithelial cells such as malignancies (39) or inflammatory conditions leading to epithelial cell necrosis or apoptosis. In addition to chronic hepatitis, non-malignant diseases associated with serum CK18 elevation include chronic lung diseases and chronic inflammatory kidney diseases $(40,41)$. Serum CK18 concentration is a function of the amount of epithelial cell death, the concentration of CK18 within these dying cells, the size of effected organ, and the probability that the contents of the dying cell will enter the general circulation. The liver is the largest solid abdominal organ with a dense population of epithelioid derived hepatocytes, which express large quantities of CK18, and the liver is centrally located so that the cellular contents enter the systemic circulation.

Therefore, the liver is a major contributor to the serum CK18 level. Malignancy and chronic lung disease rapidly become symptomatic, while chronic liver and kidney diseases may be asymptomatic for long periods of time. We have over 10 years of clinical follow up data on all subjects, which by in large were healthy workers. During the follow up interval, only 1 subject was diagnosed with cancer, and this diagnosis was made four years after the date of serum sample collection. Thus the possibility that the elevated CK18 levels observed in this study were due to unidentified malignancies is remote. Furthermore, none of the workers with elevated CK-18 levels in group 2 had active pulmonary or renal diseases (by history, physical exam or labs - data not shown), although three workers reported having pneumonia within 3 months of the serum sample collection date. Thus, the absence of malignancy and chronic lung/kidney disease suggests that the observed serum CK18 elevations were due to chronic liver disease. In addition to specificity, a second potential problem with using CK18 as a biomarker for chronic liver disease is that the selected cutoffs have never been rigorously validated in a liver biopsy study of TASH, but rather were based on the previously published NASH literature and our own experience with vinyl chloride-related TASH studies $(1,22,27)$. Anecdotally, however, liver-related mortality has not historically been greater than expected in this cohort of ABS workers, and modern-day exposures may be less than those experienced by this cohort. The findings of our study coupled with these historical observations call for future liver biopsy studies to rigorously validate CK18 as a biomarker for TASH and for the precise determination of its sensitivity and specificity at various cutoffs in present-day ABS workers. Of minor concern, viral hepatitis serologies were not determined in this study. Furthermore, a non-exposed healthy control group was 
not included for comparison of CK18 and cytokine levels. However, excluding subjects with viral hepatitis is not likely to influence our results because chronic hepatitis B is extremely rare in Caucasians in this region and the prevalence of chronic hepatitis $\mathrm{C}$ is expected to be less than or equal to the overall US national average which is only 2.2 to $2.4 \%$ in adults (42). Our lab has determined mean CK18 and cytokine levels for a healthy unexposed control group and these results have been previously published (1). Anecdotally, workers in the present study had higher mean CK18, IL-6, IL-8, and TNF $\alpha$ levels than the unexposed healthy controls from that study.

In conclusion, 39\% of acrylonitrile, 1,3 butadiene, and styrene-exposed elastomer/polymer workers had elevated serum cytokeratin 18 levels suggestive of liver disease. Proinflammatory cytokines previously implicated in toxicant-associated steatohepatitis were elevated in effected workers. Future ultrasound and liver biopsy studies should be performed in chemical workers with biochemical signatures consistent with occupational liver disease and suspected toxicant-associated steatohepatitis.

\section{Acknowledgments}

Grant Information: This research was supported in part by the National Institute of Environmental Health Sciences (P30ES014443-01A1, T35ES014559), the National Institute on Alcohol Abuse and Alcoholism (K23AA18399-01A, 1P01AA017103-01), the National Center for Research Resources (5P20RR024489-02), the Department of Veterans Affairs, the Commonwealth of Kentucky (The University of Louisville Clinical \& Translational Science Pilot Grant Program Advanced Award), and the National Institutes of Health Loan Repayment Program.

\section{Abbreviations}

ABS

ALT

ASH

AST

CK18

CK18 M30

CK18 M65

CERM

Cyp2E1

IL-6

GST

IL-8

MCP-1

NASH

OSHA

PAI-1

TASH

TNFa acrylonitrile, butadiene, and styrene

alanine aminotransferase

alcoholic hepatitis

aspartate aminotransferase

cytokeratin 18

cytokeratin 18 caspase-cleaved fragment or M30 antigen

cytokeratin 18 whole protein or M65 antigen

cumulative exposure rank month

cytochrome P450 2E1

interleukin-6

glutathione S-transferase

interleukin-8

monocyte chemotactic protein-1

nonalcoholic steatohepatitis

Occupational Safety and Health Administration

plasminogen activator inhibitor-1

toxicant-associated steatohepatitis

tumor necrosis factor $\alpha$ 


\section{References}

1. Cave M, Falkner KC, Ray M, et al. Toxicant-associated steatohepatitis in vinyl chloride workers. Hepatology (Baltimore, Md). 2010; 51:474-481.

2. Thiele DL, Eigenbrodt EH, Ware AJ. Cirrhosis after repeated trichloroethylene and 1,1,1trichloroethane exposure. Gastroenterology. 1982; 83:926-929. [PubMed: 7106523]

3. Zimmerman, H. Hepatotoxicity: The Adverse Effects Of Drugs And Other Chemicals On The Liver. Philadelphia: Lippincott Williams \& Wilkins; 1999.

4. Creech JL Jr, Johnson MN. Angiosarcoma of liver in the manufacture of polyvinyl chloride. J Occup Med. 1974; 16:150-151. [PubMed: 4856325]

5. Mastrangelo G, Fedeli U, Fadda E, et al. Increased risk of hepatocellular carcinoma and liver cirrhosis in vinyl chloride workers: synergistic effect of occupational exposure with alcohol intake. Environmental health perspectives. 2004; 112:1188-1192. [PubMed: 15289165]

6. Mundt KA, Dell LD, Austin RP, Luippold RS, Noess R, Bigelow C. Historical cohort study of 10 109 men in the North American vinyl chloride industry, 1942-72: update of cancer mortality to 31 December 1995. Occupational and environmental medicine. 2000; 57:774-781. [PubMed: 11024202]

7. Ward E, Boffetta P, Andersen A, et al. Update of the follow-up of mortality and cancer incidence among European workers employed in the vinyl chloride industry. Epidemiology. 2001; 12:710718. [PubMed: 11679801]

8. Brautbar N, Williams J 2nd. Industrial solvents and liver toxicity: risk assessment, risk factors and mechanisms. Int J Hyg Environ Health. 2002; 205:479-491. [PubMed: 12455270]

9. Cotrim HP, Andrade ZA, Parana R, Portugal M, Lyra LG, Freitas LA. Nonalcoholic steatohepatitis: a toxic liver disease in industrial workers. Liver. 1999; 19:299-304. [PubMed: 10459628]

10. Cotrim HP, De Freitas LA, Freitas C, et al. Clinical and histopathological features of NASH in workers exposed to chemicals with or without associated metabolic conditions. Liver Int. 2004; 24:131-135. [PubMed: 15078477]

11. Cave M, Deaciuc I, Mendez C, et al. Nonalcoholic fatty liver disease: predisposing factors and the role of nutrition. The Journal of nutritional biochemistry. 2007; 18:184-195. [PubMed: 17296492]

12. Gonzalez-Quintela A, Abdulkader I, Campos J, Fernandez-Hernandez L, Lojo S. Serum levels of keratin-18 fragments [tissue polypeptide-specific antigen (TPS)] are correlated with hepatocyte apoptosis in alcoholic hepatitis. Dig Dis Sci. 2009; 54:648-653. [PubMed: 18618253]

13. Syn WK, Choi SS, Diehl AM. Apoptosis andcytokines in non-alcoholic steatohepatitis. Clin Liver Dis. 2009; 13:565-580. [PubMed: 19818305]

14. Feldstein AE, Wieckowska A, Lopez AR, Liu YC, Zein NN, McCullough AJ. Cytokeratin-18 fragment levels as noninvasive biomarkers for nonalcoholic steatohepatitis: A multicentervalidation study. Hepatology (Baltimore, Md. 2009

15. Nasralla SN, Ghoneim AI, Khalifa AE, Gad MZ, Abdel-Naim AB. Lactoperoxidase catalyzes in vitro activation of acrylonitrile to cyanide. Toxicology letters. 2009; 191:347-352. [PubMed: 19825401]

16. Filser JG, Faller TH, Bhowmik S, et al. First-pass metabolism of 1,3-butadiene in once-through perfused livers of rats and mice. Chemico-biological interactions. 2001; 135-136:249-265.

17. Yuan W, Jin H, Chung JK, Zheng J. Evidence for cellular protein covalent binding derived from styrene metabolite. Chemico-biological interactions. 2010; 186:323-330. [PubMed: 20470765]

18. Abdelmalek MF, Sanderson SO, Angulo P, et al. Betaine for nonalcoholic fatty liver disease: results of a randomized placebo-controlled trial. Hepatology (Baltimore, Md. 2009; 50:1818-1826.

19. Barve A, Khan R, Marsano L, Ravindra KV, McClain C. Treatment of alcoholic liver disease. Ann Hepatol. 2008; 7:5-15. [PubMed: 18376362]

20. Dannaher CL, Tamburro CH, Yam LT. Occupational carcinogenesis: the Louisville experience with vinyl chloride-associated hepatic angiosarcoma. The American journal of medicine. 1981; 70:279-287. [PubMed: 7193411]

21. Greenberg RA, Tamburro CH. Exposure indices for epidemiological surveillance of carcinogenic agents in an industrial chemical environment. J Occup Med. 1981; 23:353-358. [PubMed: 7195425] 
22. Yilmaz Y, Dolar E, Ulukaya E, et al. Soluble forms of extracellular cytokeratin 18 may differentiate simple steatosis from nonalcoholic steatohepatitis. World J Gastroenterol. 2007; 13:837-844. [PubMed: 17352011]

23. Clark JM. The epidemiology of nonalcoholic fatty liver disease in adults. Journal of clinical gastroenterology. 2006; 40 (Suppl 1):S5-10. [PubMed: 16540768]

24. Morgan DL, Mahler JF, O'Connor RW, Price HC Jr, Adkins B Jr. Styrene inhalation toxicity studies in mice. I. Hepatotoxicity in B6C3F1 mice. Fundam Appl Toxicol. 1993; 20:325-335. [PubMed: 8504906]

25. Guangwei X, Rongzhu L, Wenrong X, et al. Curcumin pretreatment protects against acute acrylonitrile-induced oxidative damage in rats. Toxicology. 2010; 267:140-146. [PubMed: 19913070]

26. Brodkin CA, Moon JD, Camp J, et al. Serum hepatic biochemical activity in two populations of workers exposed to styrene. Occupational and environmental medicine. 2001; 58:95-102. [PubMed: 11160987]

27. Vos MB, Barve S, Joshi-Barve S, Carew JD, Whitington PF, McClain CJ. Cytokeratin 18, a marker of cell death, is increased in children with suspected nonalcoholic fatty liver disease. $\mathrm{J}$ Pediatr Gastroenterol Nutr. 2008; 47:481-485. [PubMed: 18852641]

28. Zewdu M, Henry LD, Falkner KC, McClain CJ, Cave M. Serum Cytokeratin 18 and Adipocytokines in Alcoholic Hepatitis Versus Nonalcoholic Steatohepatitis [abstract]. Gastroenterology. 2010; 138:S1859.

29. Primavera A, Fustinoni S, Biroccio A, et al. Glutathione transferases and glutathionylated hemoglobin in workers exposed to low doses of 1,3-butadiene. Cancer Epidemiol Biomarkers Prev. 2008; 17:3004-3012. [PubMed: 18990742]

30. Bolt HM, Roos PH, Thier R. The cytochrome P-450 isoenzyme CYP2E1 in the biological processing of industrial chemicals: consequences for occupational and environmental medicine. International archives of occupational and environmental health. 2003; 76:174-185. [PubMed: 12690492]

31. Miller MC 3rd, Mohrenweiser HW, Bell DA. Genetic variability in susceptibility and response to toxicants. Toxicology letters. 2001; 120:269-280. [PubMed: 11323185]

32. Toshimitsu K, Matsuura B, Ohkubo I, et al. Dietary habits and nutrient intake in non-alcoholic steatohepatitis. Nutrition. 2007; 23:46-52. [PubMed: 17140767]

33. Sanyal AJ, Chalasani N, Kowdley KV, et al. Pioglitazone, vitamin E, or placebo for nonalcoholic steatohepatitis. N Engl J Med. 2010; 362:1675-1685. [PubMed: 20427778]

34. Lin YS, Smith TJ, Wypij D, Kelsey KT, Sacks FM. Association of the blood/air partition coefficient of 1,3-butadiene with blood lipids and albumin. Environmental health perspectives. 2002; 110:165-168. [PubMed: 11836145]

35. Arteel GE. New role of plasminogen activator inhibitor-1 in alcohol-induced liver injury. $\mathbf{J}$ Gastroenterol Hepatol. 2008; 23 (Suppl 1):S54-59. [PubMed: 18336665]

36. Devalaraja MN, McClain CJ, Barve S, Vaddi K, Hill DB. Increased monocyte MCP-1 production in acute alcoholic hepatitis. Cytokine. 1999; 11:875-881. [PubMed: 10547276]

37. Abe M, Oshima RG. A single human keratin 18 gene is expressed in diverse epithelial cells of transgenic mice. J Cell Biol. 1990; 111:1197-1206. [PubMed: 1697294]

38. Moll R, Franke WW, Schiller DL, Geiger B, Krepler R. The catalog of human cytokeratins: patterns of expression in normal epithelia, tumors and cultured cells. Cell. 1982; 31:11-24. [PubMed: 6186379]

39. Linder S, Olofsson MH, Herrmann R, Ulukaya E. Utilization of cytokeratin-based biomarkers for pharmacodynamic studies. Expert Rev Mol Diagn. 2010; 10:353-359. [PubMed: 20370591]

40. Chung WY, Sun JS, Park JH, et al. Epithelial apoptosis as a clinical marker in idiopathic interstitial pneumonia. Respir Med. 2010; 104:1722-1728. [PubMed: 20542676]

41. Roth GA, Lebherz-Eichinger D, Ankersmit HJ, et al. Increased total cytokeratin-18 serum and urine levels in chronic kidney disease. Clin ChimActa. 2011; 412:713-717.

42. Lao XQ, Thompson A, McHutchison JG, McCarthy JJ. Sex and age differences in lipid response to chronic infection with the hepatitis $\mathrm{C}$ virus in the United States National Health and Nutrition Examination Surveys. J Viral Hepat. 2010 
Table 1

Demographic Information and Cumulative Exposure Data

\begin{tabular}{|c|c|c|c|c|}
\hline & All Workers & Group 1 Healthy Workers & Group 2 Suspected TASH & $\begin{array}{l}\text { Group } 3 \text { Other Suspected } \\
\text { Liver Disease }\end{array}$ \\
\hline Number & 82 & 50 & 25 & 7 \\
\hline Age $(y r)$ & $47.43 \pm 7.46$ & $45.50 \pm 5.81$ & $49.38 \pm 3.87$ & $51.83 \pm 12.41$ \\
\hline BMI & $25.08 \pm 3.31$ & $25.09 \pm 3.02$ & $25.09 \pm 3.87$ & $25.00 \pm 3.67$ \\
\hline CERM-ACRYL & $1123.58 \pm 425.26$ & $1316.11 \pm 252.46$ & $805.86 \pm 476.58^{1}$ & $591.96 \pm 282.28^{1}$ \\
\hline CERM-BUT & $1055.39 \pm 449.26$ & $1240.69 \pm 327.97$ & $740.19 \pm 473.25^{1}$ & $597.98 \pm 284.53^{2}$ \\
\hline CERM-STYR & $944.00 \pm 352.68$ & $1097.73 \pm 214.42$ & $681.20 \pm 406.18^{1}$ & $571.98 \pm 252.68^{2}$ \\
\hline $\begin{array}{l}\text { Duration of Employment } \\
\text { (yr) }\end{array}$ & $21.57 \pm 9.17$ & $21.01 \pm 6.91$ & $21.58 \pm 10.39$ & $24.89 \pm 15.98$ \\
\hline \multicolumn{5}{|l|}{1 p $<0.001$ vs. group 1} \\
\hline
\end{tabular}

Note: Workers were sub-grouped by serum CK18 levels as follows: Group 1, normal CK18 M65 and M30; Group 2, Elevated M65 and normal M30; Group 3 Elevated M65 and M30. Serum CK-18 M65 was measured by ELISA and elevated levels were defined as values $\geq 300$ U/L, while serum CK-18 M30 was measured by ELISA and elevated levels were defined as values $\geq 200 \mathrm{U} / \mathrm{L}$.

Abbreviations: BMI, body mass index; CK18 M30, cytokeratin 18 caspase 3-cleaved fragment; CK18 M65, soluble cytokeratin 18; CERMACRYL, cumulative exposure rank month for acrylonitrile; CERM-BUT, cumulative exposure rank month for 1,3-butadiene; CERM-STYR, cumulative exposure rank month for styrene; TASH, toxicant-associated steatohepatitis. 
Table 2

Serum Liver Tests, Glucose, and Triglycerides

\begin{tabular}{lllll}
\hline & All Workers & $\begin{array}{l}\text { Group 1 Healthy } \\
\text { Workers }\end{array}$ & Group 2 Suspected TASH & $\begin{array}{l}\text { Group 3 Other Suspected } \\
\text { Liver Disease }\end{array}$ \\
\hline Number & 82 & 50 & 25 & 7 \\
ALT (0-55 U/L) & $18.36 \pm 14.67$ & $14.82 \pm 14.1$ & $23.67 \pm 11.98^{1}$ & $25.43 \pm 20.53$ \\
AST (0-50 U/L) & $19.32 \pm 6.87$ & $19.88 \pm 7.54$ & $17.63 \pm 5.44$ & $21.14 \pm 5.81$ \\
ALK PHOS (25-140 U/L) & $73.32 \pm 21.05$ & $69.94 \pm 17.69$ & $78.13 \pm 26.71$ & $84.00 \pm 16.67$ \\
Bilirubin (0.2-1.2 mg/dL) & $0.61 \pm 0.27$ & $0.57 \pm 0.27$ & $0.64 \pm 0.28$ & $0.74 \pm 0.26$ \\
Albumin (3.5-5.5 mg/dL) & $4.26 \pm 0.26$ & $4.22 \pm 0.26$ & $4.3 \pm 0.28$ & $4.4 \pm 0.16$ \\
Glucose (70-110 mg/dL) & $105.21 \pm 27.05$ & $108.70 \pm 33.04$ & $99.28 \pm 10.33$ & $101.20 \pm 6.76$ \\
Triglycerides (<200 mg/dL) & $166.39 \pm 131.03$ & $167.73 \pm 153.99$ & $163.29 \pm 67.25$ & $167.17 \pm 130.36$ \\
CK-18 M65 (<300 U/L) & $247.34 \pm 196.33$ & $107.57 \pm 63.36$ & $444.43 \pm 87.98^{2}$ & $541.88 \pm 175.32^{2,3}$ \\
CK-18 M30 (<200 U/L) & $78.55 \pm 91.61$ & $32.80 \pm 38.62$ & $103.19 \pm 38.51^{1}$ & $317.30 \pm 93.31^{1,4}$ \\
CK-18 M30/M65 ratio (\%) & $32.70 \pm 31.60$ & $33.43 \pm 37.34$ & $23.06 \pm 7.64$ & $61.90 \pm 21.82^{3,5}$ \\
\hline
\end{tabular}

$1_{\mathrm{p}}<0.05$ vs. group 1

2

p $<0.001$ vs. group 1

3 p $<0.05$ vs. group 2

$4 \mathrm{p}<0.001$ vs. group 2

$5 \mathrm{p}<0.01$ vs. group 1.

Note: Workers were sub-grouped by serum CK18 levels as follows: Group 1, normal CK18 M65 and M30; Group 2, Elevated M65 and normal M30; Group 3 Elevated M65 and M30. The provided normal reference ranges were determined by the hospital lab except for fasting glucose where upper limit of normal was defined by World Health Organization, and cytokeratin 18 which was defined by the investigators as CK18 M65 $<300$ U/L, CK18 M30 <200 U/L. Serum CK18 M65 and M30 were measured by ELISA.

Abbreviations: ALT, alanine aminotransferase activity; AST, aspartate aminotransferase activity; ALK PHOS, alkaline phosphatase; CK18 M30, cytokeratin 18 caspase 3-cleaved fragment; CK18 M65, soluble cytokeratin 18 whole protein. 


\section{Table 3}

Linear Regression Analysis Between Serum Cytokeratin 18 M65 and Serum Aminotransferases and Proinflammatory Cytokines

\begin{tabular}{lll}
\hline & $\mathbf{r}^{2}$ & p-value \\
\hline AST & 0.0012 & 0.7608 \\
ALT & 0.1732 & 0.0001 \\
TNF $\alpha$ & 0.5596 & $<0.0001$ \\
IL-6 & 0.4219 & $<0.0001$ \\
IL-8 & 0.1307 & 0.0009 \\
MCP-1 & 0.1625 & 0.0002 \\
PAI-1 & 0.05157 & 0.0626 \\
\hline
\end{tabular}

Abbreviations: ALT, alanine aminotransferase; AST, aspartate aminotransferase; IL-6, interleukin-6; IL-8, interleukin-8; MCP-1, monocyte chemotactic protein-1; PAI-1, plasminogen activator inhibitor-1; TNF $\alpha$, tumor necrosis factor $\alpha$. 


\section{Table 4}

Serum Pro-inflammatory Cytokines

\begin{tabular}{|c|c|c|c|c|}
\hline & All Workers & Group 1 Healthy Workers & Group 2 Suspected TASH & Group 3 Other Suspected Liver Disease \\
\hline Number & 82 & 50 & 25 & 7 \\
\hline $\mathrm{TNF} \alpha(\mathrm{pg} / \mathrm{ml})$ & $3.83 \pm 5.41$ & $0.73 \pm 2.35$ & $9.76 \pm 5.02^{1}$ & $5.72 \pm 4.78^{2}$ \\
\hline IL-6 (pg/ml) & $3.64 \pm 4.50$ & $1.62 \pm 2.85$ & $7.45 \pm 4.92^{1}$ & $4.98 \pm 4.01^{4}$ \\
\hline IL-8 (pg/ml) & $3.05 \pm 4.29$ & $1.79 \pm 2.92$ & $5.67 \pm 5.78^{2}$ & $3.01 \pm 2.64$ \\
\hline MCP-1 (pg/ml) & $218.13 \pm 145.48$ & $179.48 \pm 151.21$ & $283.14 \pm 122.63^{3}$ & $243.76 \pm 101.71$ \\
\hline PAI-1 (ng/ml) & $24.60 \pm 33.88$ & $15.40 \pm 15.65$ & $42.57 \pm 50.94^{3}$ & $17.09 \pm 7.11$ \\
\hline \multicolumn{5}{|c|}{ 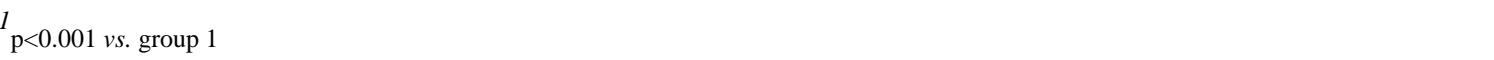 } \\
\hline \multicolumn{5}{|c|}{$2 \mathrm{p}<0.01$ vs. group 1} \\
\hline \multicolumn{5}{|c|}{$3_{\mathrm{p}}<0.05$ vs. group 1} \\
\hline${ }^{4} \mathrm{p}<0.05$ vs. group & & & & \\
\hline
\end{tabular}

Abbreviations: IL-6, interleukin-6; IL-8, interleukin-8; MCP-1, monocyte chemotactic protein-1; PAI-1, plasminogen activator inhibitor-1; TNF $\alpha$, tumor necrosis factor $\alpha$. 